Importancia, presencia y salvoconducto: acercamiento a las bandas de música en la guerra civil española (1936-1939)

Importance, presence and salvoconduct: music bands in the Spanish Civil War (1936-1939)

MARCO ANTONIO DE LA OSSA MARTÍNEZ marcoantoniodela@gmail.com

Facultad de Educación de Cuenca

\section{Aceptado 21/11/2018}

\section{Resumen}

Las bandas de música fueron las principales transmisoras de himnos, canciones y marchas en la guerra civil española (1936-1939). Su número se multiplicó en estos trágicos momentos, ya que interpretaron la banda sonora en la vida diaria de los distintos actos, cuerpos, batallones y destacamentos militares de ambos bandos; también de las gentes que quedaron en las poblaciones de retaguardia. En primer lugar, en este artículo nos aproximaremos a la historia de las bandas de música en España para, a continuación, abordar la relevancia de estas agrupaciones durante este conflicto bélico.

\section{Palabras clave}

Bandas de música · Guerra Civil Española $\cdot$ Marchas

Himnos - Cancionero de guerra

\section{Abstract}

Bands of music were the main transmitters of hymns, songs and marches in the Spanish civil war (1936-1939). Their number multiplied in these tragic moments, since they interpreted the soundtrack in the daily life of the different acts, bodies, battalions, detachments and of the people who remained in the rearguard populations. In this article we will first approach the history of music bands in Spain, and then address the relevance of these groups during this war.

\section{Keywords}

Bands of music · Spanish Civil War · Marches · Hymns · War Songbook 


\section{Introducción. Acercamiento \\ a la historia de las bandas de música en España}

Como es bien sabido, tras una rebelión militar en julio de 1936 se inició la guerra civil española, un conflicto bélico dramático y horrible que tiñó de sangre y odio al país hasta su finalización, en abril de 1939, aunque la represión posterior se prolongó varias décadas. En la vida de la España previa a 1936, las bandas de música eran formaciones muy populares que acompañaban las celebraciones, fiestas y otros momentos relevantes en el devenir de los pueblos y ciudades de la vieja piel de toro desde siglos atrás; también ponían el contrapunto sonoro a las actividades y maniobras en los que se vieron envueltos sus ejércitos y facciones militares.

Así y si buceamos brevemente en su origen y desarrollo, las bandas de música poseen un claro trasfondo guerrero. Como apuntó Bernardo Adam Ferrero,

El origen, manifestación y desarrollo de las Bandas de Música tienen su esencia o punto de arranque en la milicia. Ya en los pueblos primitivos se utilizaba para la comunicación una gran variedad de instrumentos de percusión, como tambores de distintos tamaños y formas. Posteriormente se introducen instrumentos de viento, como silbatos de hueso, cuernos y caracolas. Más tarde, y en Oriente Medio, aparecen flautas, bocinas, trompetas y cuernos metálicos de una forma ya más definida (1986: 10).

En la guerra civil española, el concurso de las bandas de música se tornó fundamental. Prácticamente, podemos afirmar que "en ambos bandos, republicano y nacionalista, su número y actividad fue, además de muy numeroso, enormemente importante" (Ossa, 2017: 22). De esta forma, estuvieron presentes en el día a día de batallones, secciones militares, frente y retaguardia. También acompañaron y acompasaron los acontecimientos más relevantes del conflicto y del triste y dramático día a día que se sufrió en España.

Por desgracia, el binomio guerra y música ha estado presente, de una u otra forma, en la historia de la humanidad, prácticamente desde los albores de su existencia:

Si el arte de los sonidos es, como se ha dicho muchas veces, $\tan$ viejo como el mundo, no sería aventurado añadir que la música militar, al menos en su especialidad de la transmisión de órdenes, su más pura y simple expresión, puede considerarse tan antigua como los enfrentamientos entre grupos de hombres (Fernández de Latorre, 2000: 34).

Como apuntamos, ambas, música y guerra, han acompañado al hombre y la mujer en el devenir de la historia. Por ello y en este sentido, la música militar y el consiguiente concurso de agrupaciones musicales han tenido una función sustancial. De esta manera, cada tribu, milicia, facción o ejército pronto contó con sus propios toques y sonidos. Así y a medida de señales conocidas por todos sus componentes, avisaban a los miembros de su sección del peligro de un ataque, convocaban a los soldados en un punto determinado, marcaban el tempo del paso en traslados y desfiles, trataban de imprimir el arrojo, carácter y valor necesario para afrontar la lucha, indicaban el momento de atacar o de batirse en retirada, divertían a soldados y civiles en tiempos muertos...

Quizá sea interesante realizar un breve recorrido por la tradición musical bélica en España. Según Fernández de Latorre, que cita a Hermann Schmidt, la historia de la música militar en España se puede estructurar en tres etapas: "la primera, desde los tiempos más remotos hasta la Edad Media; la segunda, hasta el siglo XVIII y la tercera, de entonces a nuestros días" (2000: 25).

Durante la estancia árabe y en tiempos de la Reconquista, los distintos ejércitos destacaron por el empleo de diferentes conjuntos instrumentales, que fueron muy ricos en instrumentos de percusión, en el caso de los primeros. Es más: en muchos casos la primera aparición en Europa de instrumentos de percusión de membrana se debe a la presencia de esta cultura:

Tanto el ejército moro como el cristiano poseen grupos instrumentales, como el del caudillo árabe Tarik, invasor de España en 711, cuyo cuerpo de timbaleros precedía a sus tropas. Igualmente el rey Fernando el Católico se hacía acompañar por una formación músico-militar con sones de trompetas bastardas, atabales y tambores (Adam, 1986: 10). 
En consecuencia, uno de los principales objetivos de estas agrupaciones instrumentales fue el de intentar intimidar a los peninsulares. Incluso, introducían dentro del parche fragmentos de metal o pequeñas campanas que aumentaban su efecto. Diferentes episodios del Poema del Mío Cid parecen reafirmar este hecho señalando el pavor que provocaban entre las tropas del Campeador. De esta forma, parece probado el desconocimiento de estos instrumentos en la lbérica y el miedo que estos causaban, aunque pronto serían asumidos y utilizados por los ejércitos castellano y aragonés. Por ejemplo, en el verso 696 se indica "ante roído de atambores la tierra quiere quebrar." Y, entre los versos 1663 y 1669 ,

...en el pasaje en que Yusuf, Rey de Marruecos, intenta conquistar Valencia, se incide en el gran temor que causaban los tambores árabes a los cristianos, y escuchamos cómo trata el Cid de acallar la aprehensión de los suyos, prometiendo que esos instrumentos serían ganados al enemigo, mostrados a los propios para que vean que son obra del hombre y llevados después como trofeos a una iglesia (Fernández de Latorre, 2000: 36).
De igual forma, la presencia de formaciones instrumentales en el recibimiento y homenaje (también en las celebraciones posteriores) a los soldados tras vencer en alguna batalla aparecen relatados en numerosas ocasiones:

Con los ministriles, en el siglo XIII, aparecen diversas formaciones instrumentales de viento en desfiles, procesiones, etcétera. Conjuntos agrupados y protegidos por las catedrales para acompañar el culto en sus capillas musicales. Esto se extiende a los pertenecientes al servicio de grandes señores (Adam, 1986: 25).

Avanzando en el tiempo, en el siglo XVI los ejércitos españoles contaban con tambores y pífanos que acompañaban sus acciones bélicas. Éste fue un momento de gran relevancia en la historia de la música militar, ya que "aparecieron referencias musicales bélicas en formas tan diversas como en los tientos de batalla creados por los grandes organistas de la época renacentista o las llamadas Misas de Batalla" (Ossa, 2017: 24). También se iniciaron los llamados toques de oración, piezas que se interpretaban en honor a los caídos en batalla. Al parecer, fue una iniciativa de un militar de gran importancia en estos momentos, el Gran Capitán:

En el haber del Gran Capitán hay que anotar el punto de partida de un toque que iniciaría en el mundo militar el homenaje a los soldados muertos por la Patria. Se dice que, tras la batalla de Ceriñola, el 28 de abril de 1503, contemplando el cuerpo sin vida de un joven adversario, el vencido duque de Nemours, que yacía junto a tres mil de sus hombres, Gonzalo ordenó que se interpretase un toque lúgubre que durase el tiempo que se invertía en rezar un Padrenuestro (Fernández de Latorre, 2000: 54).

La Iglesia también potenció la creación de música impregnada de claras influencias castrenses e, incluso, hay presencia de la misma en cancioneros, como los de Palacio, en obras en la que se narraban las hazañas de soldados y generales.

Posteriormente, crecieron y se desarrollaron agrupaciones de instrumentos de viento que actuaron en procesiones, desfiles y en otros actos celebrados en catedrales y centros eclesiásticos. Además, a mediados del siglo XVIII se fue aumen- tando progresivamente el número de ejecutantes. Al mismo tiempo, se fueron incorporando nuevos instrumentos. Paulatinamente, la paleta de la formación se amplió añadiendo más instrumentos de viento procedentes de las orquestas cultas, como trompas, oboes, clarinetes, fagotes, flautas, trompetas y contrabajo o serpentón; también instrumentos de percusión como platillos, triángulos, bombos..

El atambor mayor, un músico que dirigía las bandas de viento y percusión, apareció por primera vez en los ejércitos españoles, y su figura pronto se extendió a los de todo el mundo. Portaba un bastón con el que, a modo de director, indicaba el compás de una forma llamativa y, a veces, acrobática.

En el siglo XIX surgió y se desarrolló la banda de música tal y como las conocemos en la actualidad. Las notables mejoras técnicas sufridas por los instrumentos de viento fueron la causa directa de su crecimiento y entrada definitiva en la agrupación. La presencia de las agrupaciones que acompañaban a los ejércitos napoleónicos en la guerra de la Independencia se convirtió en un acicate para la evolución de una formación que, en Es- 
paña, se integraba por la mitad de componentes y no poseían una estructura reglamentaria:

Los franceses trajeron con sus ejércitos magníficas bandas de música. Según François Joseph Fétis, el famoso musicólogo belga, en los años que corresponden la invasión de nuestra Patria, las bandas napoleónicas de infantería contaban con veintidós o veinticuatro ejecutantes: seis $u$ ocho clarinetes grandes, un clarinete pequeño en mi bemol (puede ser un equivalente al actual requinto), un flautín, dos trompas, dos fagotes, una trompeta, dos o tres trombones, uno o dos serpentones (tubas), bombo, platillos, caja y chinesco. Naturalmente, estos grupos no estaban integrados en su totalidad por músicos profesionales, de los que formaban solo unos diez o doce, siendo los restantes, soldados educandos (Fernández de Lato-

$$
\text { rre, 2000: 134). }
$$

En 1875, las bandas de música militares se regularon en la Real Orden de 7 de agosto gracias al Reglamento para la Organización de las Músicas y Charangas de los Cuerpos de Infantería y Regimientos a
Pie de las demás Armas e Institutos. En la misma, se dispuso que las agrupaciones se compusieran de

...un músico mayor, cinco músicos de primera clase, diez de segunda, veinticinco de tercera y veinte educandos. Total: sesenta instrumentistas. Para las Batallones independientes, un músico mayor, tres de primera clase, seis de segunda, veintiuno de tercera y dieciséis educandos. Total: cuarenta y seis instrumentos (Fer-

nández de Latorre, 2000: 296).

La gran importancia que las bandas militares fueron poseyendo en sus múltiples actividades hizo crecer la necesidad de crear nuevas formaciones musicales. De esta manera, se puede atender a su gran relevancia tanto en su vertiente principal como en otra más popular. Progresivamente, en el ámbito civil se analizaron y consideraron los beneficios de contar con una formación instrumental que acompañara y otorgara contrapunto sonoro y solemnidad a los actos que vertebraban la vida diaria de pueblos y ciudades.

Al mismo tiempo, se contaba con un grupo de ejecutantes que también podían actuar como docentes para formar musical e instrumentalmente a las nue vas generaciones. Por tanto, las bandas se convirtieron en un instrumento de primer orden con el que trasladar la cultura y la música a toda la sociedad. Además, a ellas se debe la transmisión de numerosísimas obras de diferentes géneros y estéticas.

\section{Las bandas de música en la guerra civil española}

Centrándonos en la trágica etapa de la guerra civil española, la mayor parte de las formaciones parecieron continuar e trabajo iniciado anteriormente. Eso sí, tu vieron que adaptar su nombre y adecuar los repertorios a las circunstancias de conflicto y a la zona en la que se situaban. Incluso, las bandas militares parecieron multiplicarse para atender al gran número de facciones que pronto surgieron, ya que su concurso se tornó fundamental en ambos bandos. El motivo es que eran muy numerosos los múltiples actos en los que se requería su presencia y en los que la música debía estar presente.

De esta forma, "un buen número de batallones, divisiones y cuerpos de los distintos ejércitos o secciones contaron con el concurso de una banda de músi- ca" (Ossa, 2011: 83). Lo cierto es que, curiosamente, este hecho alejó de la lucha directa en primera línea de fuego a los músicos: tocar un instrumento de viento o percusión significaba que el recluta o voluntario pasaba directamente a formar parte de una de estas formaciones $y$, en consecuencia, no realizaban acciones guerreras directamente, sino que acompañaban a las mismas.

Por ello, el número de muertes y heridas sufridas por estos intérpretes parece mucho menor si lo comparamos con el del resto de hombres de su misma edad llamados a filas o enrolados voluntariamente. Por tanto, cabe afirmar que la música, para los jóvenes músicos, fue una especie de visado que les libró de batirse en las primeras líneas del frente.

Habitualmente, el número de los componentes de estas agrupaciones podía rondar los cincuenta miembros aunque, en muchos casos, era menor. Este es el caso de la Banda de Música 'Libertad' de Bilbao, que contaba, a fecha de 1 de octubre de 1936, con

Director, 1 flautín, 2 flautas, 1 fa got, 1 requinto, 9 clarinetes, 4 saxofones altos, dos saxos tenores, 6 
trompetas, 1 fliscornos, cuatro trombones, dos bombardinos, 1 barítono 3 bajos, dos cajas, 1 platillo, 1 bombo, 1 copista y archivero, 1 copista y secretario, 1 copista y mozo atrilero (AGGCE 1/217/19)

En conjunto, el papel jugado por las bandas en ambas zonas poseyó una gran relevancia. Pronto se convirtieron en uno de los principales vehículos de transmisión de himnos y marchas, aunque también interpretaron otros repertorios. En el caso del bando nacionalista, "las bandas de la Legión, del Requeté de Navarra, de las Milicias de Fe de las Juntas de Ofensiva Nacional Sindicalista (JONS), de Salamanca, San Marcial y la del Ejército del Aire fueron las más importantes" (Ossa, 2011 86). Además y gracias a las grabaciones discográficas, la radio en zona franquista funcionó como medio de difusión de las nuevas obras compuestas.

A través de las ondas también se propagaron obras de carácter militar pertenecientes a épocas anteriores. Del mismo modo, se siguieron interpretando aquellas obras que formaban parte de su repertorio y se consideraban adecuadas a momento en el que se vivía en ambas orillas.
La presencia de fuerzas extranjeras como las nazis, italianas o las regulares marroquíes también tuvo su reflejo en las bandas de música. La Legión Cóndor alemana "trajo consigo una formación de músicos compuesta por tambores, trompetas y cornetas" (Ossa, 2011: 86). Al mismo tiempo, las tropas de Hitler contaron con un conjunto musical integrado por treinta intérpretes que tuvo base en Zaragoza y actuó en un buen número de ciudades.

Así, la ofensiva franquista de Cataluña fue seguida por esta agrupación alemana. Habitualmente actuó en los pueblos y ciudades que eran tomados por el bando nacionalista. Con respecto a las fuerzas italianas fascistas, al parecer no se acompañaron de músicos durante la contienda española. Por último, las Bandas de las Fuerzas Regulares Indígenas gozaban de una amplia trayectoria desde su creación en 1911 y también estuvieron presentes en España

De igual modo, la zona republicana vivió una enorme proliferación de bandas. De todas ellas, destacaron la Banda Republicana, la del Quinto Regimiento o la de Barcelona, entre muchísimas otras. En cuanto al repertorio interpretado, el Himno de Riego continuó siendo el himno oficial de la República, aunque pronto se incorporaron otros tomados también como oficiales por la diversidad de sindicatos, partidos y facciones que se integraban en el Frente Popular. Entre ellos, "cabe citar La Internacional socialista o A las barricadas anarquista" (Ossa, 2017: 34). Gran parte de los himnos y marchas que se habían popularizado durante la Segunda República continuaron interpretándose en alternancia con nuevas creaciones.

Durante el conflicto bélico, la creación de marchas e himnos militares fue una constante, tal y como se puede señalar atendiendo al número de obras registradas en la Sociedad de Autores y a los concursos públicos de composición que se organizaron en ambos bandos. Como ocurrió en el bando franquista, se dedicaron a la Marina, a secciones del Ejército de Tierra, del Aire y a mandos, generales o unidades en particular. De esta manera, "un gran número de batallones y divisiones fomentaron la composición de una obra que les representara. Incluso, organizaron concursos con este fin" (Ossa, 2017: 34). Respecto a la existencia de bandas de música en las Brigadas Internacionales, parece que no se ha reseñado ningún caso en los estudios que se han realizado sobre el tema.

Curiosamente y a pesar del dramatismo y del horror que se vivieron en las zonas de guerra, las fiestas y los festivales, de muy distinto sino y estilo proliferaron en ambas zonas en los primeros instantes. Su objetivo era lograr fondos que iban destinados, en la mayor parte de los casos, a paliar alguna de las muchas necesidades del frente, además de divertir a las gentes de la retaguardia. En muchos de ellos, la presencia de las bandas fue fundamental, ya que se encargaron de realizar la banda sonora en diferentes actos. En este sentido, podemos citar un encuentro desarrollado en Villamayor de Santiago (Cuenca)

El próximo día 13 se celebrará en la Plaza de Toros de Alcázar de San Juan un festival musical a beneficio de las Milicias Populares, para el cual han sido invitadas varias e importantes agrupaciones, entre ellas la de Villamayor de Santiago que dirige Francisco Martínez, a la que deseamos un gran éxito (Heraldo de Cuenca, 7/9/1936: 5).

Aunque su número fue disminuyendo con el transcurso de la guerra, ya que no 
se consideraron oportunos teniendo en cuenta las privaciones y la dura realidad que se estaba viviendo en el frente, en noviembre de 1938 hay una referencia a la presencia de la Banda de Música del 12 Batallón de Retaguardia, que acudió a Motilla del Palancar (Cuenca) a protagonizar un festival. En una "Croniquilla" publicada en el número 26 de Vida Nueva (órgano provincial de la Unión General de Trabajadores), alguien que firmaba como “El Tío Serafín" critica abiertamente, además de la realización del acto, el uso que se hizo de los autobuses de línea que conectaban Cuenca con Utiel, Priego y otros pueblos, ya que los ciudadanos se quedaron por este motivo sin este servicio con el perjuicio que supuso para ellos. Además, las cartas enviadas (estos vehículos hacían las veces de coche-correo) no llegaron a su destino hasta unos días después:

El caso es, amables lectores, camaradas ugetistas, que el sábado último no hubo correo, como correspondía, para Utiel ni para Priego, ni tampoco el día de ayer. ¿Causa? El sábado por la mañana, requeridos por cierta autoridad militar -¿quién se la dio para ello y con tales perjuicios?- salió para Motilla del Palancar una expe- dición formada por los dos autobuses que hacen el recorrido de Utiel y de Priego para conducir a Motilla a la Banda de Música del 12 Batallón de Retaguardia con el fin de amenizar cierto espectáculo organizado en tal pueblo por no sabemos quién y no sabemos con qué fin. Esto produjo la supresión del correo para Utiel y pueblos de la línea, así como para Priego e ídem. Y, decimos nosotros, ¿fue derecho que porque a alguien -110 queremos saber quién ni por qué -se le ocurra en estos tiempos, tiempos de guerra y grandes preocupaciones para todos, organizar uno o varios festivales - no importa el número ni el motivo ni dóndese supriman un día (han sido dos) los servicios regulares de Correos? ¿Acaso no es más importante que puedan volver a sus pueblos multitud de ciudadanos que salieron para la capital u otros puntos y que se reciban cuanto antes las cartas de los camaradas del frente, esperadas por sus familiares con fruición? Sí, es antes lo general e imprescindible que lo superfluo, como el festival o festivales. Por ello protestamos ante el Sr. Comandante Militar por la tolerancia que se tiene con estas actividades secundarias y, además, inadmisibles, hechas por elementos militares con perjuicio del pueblo y aún de la causa. Nosotros que escribimos las "Croniquillas" con cierta ironía y broma, hoy nos vemos precisados a usar un aire de seriedad y enojo que lamentamos, pero que quisiéramos nos fuera evitado, porque se hiciera comprender a todos, militares o no, que por encima de festivales y actos de cierta guardia de escasa o nula eficacia para la causa, está el servicio público y la necesidad de normalizar la vida en la retaguardia, dentro de lo posible. Todo antes que tolerar se impida un servicio público por el capricho de cualquiera que sea y de la graduación, que sea, que tome el nombre del Ejército para "festejarse". ¿Entendido? Así lo creemos y esperamos (Vida Nueva, 8/11/1938: 4)

Aparte de las fiestas y festivales públicos, el fútbol y los toros fueron espectáculos fundamentales que se desarrollaron en ambas zonas, y en los que también estuvieron presentes las bandas de música. En el primer caso, se celebraron numerosos partidos con carácter solidario, como éste que se anunciaba en un periódico de Cuenca en 1936, en la que se refleja la asistencia de una formación musical:"mañana martes, a las tres de la tarde, fútbol: selección del batallón Palacio-Uribes contra Cuenca Sporting Club. A beneficio del S.R.I. ${ }^{1}$ Asistirá la Banda del Batallón" (Heraldo de Cuenca, 30/11/1936: 6).

En lo referente a los toros, también se llevaron a cabo corridas, becerradas y otros festivales taurinos con un claro sentido económico y de recaudación de fondos. Valga como ejemplo la que se desarrolló en noviembre de 1936 en la localidad conquense de Villamayor de Santiago: "a beneficio de los Hospitales de Sangre e iniciada por los valientes soldados de este pueblo que gozan de permiso, se ha celebrado una becerrada" ( $\mathrm{He}$ raldo de Cuenca, 9/11/1936: 8).

En muchos de ellos se decoraban las plazas con los símbolos y emblemas propios de cada bando, tal y como se comenta en la crónica de una corrida celebrada en Cuenca en 1936: "el ruedo aparecía artísticamente decorado con el escudo de la República y fases alusivas al momento actual" (Heraldo de Cuenca 9/11/1936: 10)

1 Socorro Rojo Internacional 
En este mismo acto, la Banda Municipal de Música de Cuenca también actuó: "a las cuatro y media en punto aparecen en el redondel, ocupando un automóvil descubierto y seguidas de la Banda Municipal de Música, que interpreta el Himno Nacional, las bellas y simpáticas presidentas" (Heraldo de Cuenca, 9/11/1936: 7).

Lo mismo sucedió en Villamayor de Santiago en el caso de una becerrada local de carácter benéfico:

A beneficio de los Hospitales de Sangre e iniciada por los valientes soldados de este pueblo que gozan de permiso, se ha celebrado una becerrada... Prestó su concurso la infinidad de veces laureada Banda Municipal unificada, digámoslo así, ya que actualmente se compone de elementos de la Nueva y la Vieja y que en la mejor armonía se han unido en bien del arte lírico y de pasadas rencillas, dirigidas por el inteligente maestro Martínez Córdoba interpretó escogidas obras finalizando en "La Internacional" (Heraldo de Cuenca, 9/11/1936: 2).
Los mítines y reuniones de carácter político fueron otros de los actos en los que participaron. En ellos y en el caso republicano, frecuentemente se interpretaban himnos y canciones del Frente Popular:

Con un lleno imponente, a las seis de la tarde del día 2 y en el Teatro Cervantes celebrase el acto anunciado horas antes y en el que habían de intervenir un representante del Comité de Enlace, otro de la 21 Brigada y uno de cada organización sindical... Al comenzar el acto, la Banda de Música de la 21 Brigada interpreta el himno proletario'La joven guardia' siendo muy aplaudida y coreada por toda la concurrencia (Heraldo de Cuenca, 7/12/1936: 2).

Las inauguraciones de nuevas dependencias también contaron con el concurso de bandas de música. En este caso, la Banda de Música del 20 Cuerpo del Ejército, dirigida por el maestro Pinilla, actuó en la inauguración de un bar en Cuenca para servicio de heridos y el personal del mismo. Esta misma formación también acompañó las visitas a la ciudad de personalidades políticas y militares:
Con asistencia de Martínez Barrio se hace entrega de su estandarte al Batallón de Cuenca, no 2. El desfile por Carretería fue emocionante. Sin público y previo anuncio, el pasado jueves llegó a esta capital desde Albacete, el Presidente de las Cortes, don Diego Martínez Barrio, acompañado del general Monje, del ex ministro Blanco Garzón y de varios diputados y jefes del Ejército popular. A las cinco de la tarde, en el Parque de Canalejas, sin que se anunciaran públicamente, por lo que el éxito de fue mayor y más estimable la extraordinaria concurrencia, se verificó la entrega del estandarte oficial al Batallón de Cuenca no 2 del Ejército voluntario, que se está formando. El general Martínez Monte hizo la entrega al Coronel del Batallón, entre grandes aplausos, en tanto la Banda Municipal interpretaba el himno nacional (Heraldo de Cuenca, 28/9/1936: 5).

Del mismo modo, se realizaron numerosos homenajes que contaron con la presencia de una banda de música. Po ejemplo, en el Teatro Cervantes de Cuenca en julio de 1938 se efectuó un evento para aplaudir el trabajo que estaban desarrollando numerosas mujeres, ya que tuvieron que desarrollar labores que antes realizaban hombres que fueron Ilamados a filas. En él, actuó una banda de música, en este caso la del Batallón no 12 :

Ayer, en el Teatro Cervantes, tuvo lugar un acto homenaje a la mujer conquense, incorporada al trabajo en sustitución de los hombres movilizados. El salón estaba completamente ocupado por el público y presidió el Gobernador Civil, quien as como el camarada Isaac Moya, alcalde de la capital, dirigió la palabra a la concurrencia, explicando la significación del acto e instando a todos, hombres y mujeres para intensificar el trabajo en todos los órdenes, para facilitar así la victoria sobre el fascismo. Ambos oradores hicieron resaltar el concurso que la mujer conquense viene prestando al trabajo en la construcción de refugios y la colaboración que a las autoridades prestan las distintas organizaciones de mujeres antifascistas de esta capital y provincia, cuya labor es digna de aplauso. Como complemento del acto, el Cuadro Artístico que viene actuando en el Teatro-Hogar, repre- 
sentó algunos números que fueron muy aplaudidos, y la Banda de Música del Batallón no 12 interpretó escogidas piezas de su repertorio (Vida Nueva, 12/7/1938: 9).

\section{Conclusión}

Como se ha tratado de plasmar en este breve artículo, las bandas de música fueron una formación de gran importancia en el ámbito musical de la guerra civil española. Así, tuvieron que adaptarse a las circunstancias y trasladar los repertorios que en cada zona se consideraron básicos: himnos anteriores y nuevos, marchas relacionadas con el ámbito castrense, canciones y marchas revolucionarias... Además, la composición musical también se centró en marchas e himnos, principalmente.

En el mismo sentido, la proliferación de bandas militares o asociadas a los diferentes estamentos fue muy reseñable, ya que multiplicaron su número y actividad. Como apuntamos, se convirtieron en una especie de salvoconducto para los músicos de viento y percusión que se enrolaron de forma obligatoria o voluntariamente en alguna de las dos facciones, ya que les evitó tener que empuñar las armas y acudir a guerrear a las primeras líneas de fuego.

\section{Referencias bibliográficas}

\subsection{Libros y monografías}

Adam Ferrero, B. (1986). Las bandas de música en el mundo. Madrid: Ediciones Sol.

Fernández de Latorre, R. (2000). Historia de la música militar en España. Madrid: Ministerio de Defensa.

Moreno Martín, N. F. (2007). El sonido de la vida. Banda municipal de música de Soria. Soria: Diputación Provincial de Soria.
Ossa Martínez, M. A. de la (2011). La música en la guerra civil española. Cuenca/Madrid: SEdeM/Servicio de Publicaciones de la Universidad de Castilla-La Mancha.

(2017). Repertorio, historia y vivencias en la retaguardia: Ia Banda Municipal de Música de Cuenca en la guerra civil española. Albacete: Uno Editorial.

Sopeña, F. (1976). Historia de la música española contemporánea. Barcelona: Rialp.

Sorozábal, P. (1986). Mi vida y mi obra. Madrid: Fundación Banco Exterior.

\subsection{Artículos de periódicos y revistas}

Heraldo de Cuenca, 81, 7/9/1936.

Heraldo de Cuenca, 89, 28/9/1936.

Heraldo de Cuenca, 98, 9/11/1936

Heraldo de Cuenca, 102, 7/12/1936

Vida Nueva, 9, 12/7/1938.

Vida Nueva, 26, 8-11-1938.

\subsection{Documentos de archivos}

AGGCE (Archivo General de la Guerra Civil Española), Política Social, SANTANDER_A, C. 217 , Exp. 1/217/19 